\title{
Multiple-Purchaser Payments for Ecosystem Services: An Exploration Using Spatial Simulation Modelling
}

\author{
Gregory Smith ${ }^{1}$ (D) Brett Day ${ }^{1} \cdot$ Amy Binner $^{1}$
}

Accepted: 12 February 2019 / Published online: 20 February 2019

(c) The Author(s) 2019

\begin{abstract}
This paper focuses on the issue of payments for ecosystem services (PES) mechanism design when the activity incentivised through the scheme benefits multiple groups, each of whom might be prepared to contribute to payments made through the scheme. In particular, we examine spatial coordination on the demand side of the market; that is to say, the question of which beneficiary of the PES scheme buys land-management changes on which land parcels. We show through spatial simulation modelling that it is possible for negotiation to lead to Pareto improvements when compared to solutions reached through non-cooperative strategic solutions; however, we also show that this result is not universal and only holds under certain conditions. In particular, the spatial correlation and spatial interdependence of the ecosystem service benefits are key in determining whether negotiation between beneficiaries is optimal and therefore if policy makers and designers of PES schemes should be prioritising bringing together multiple beneficiaries of ecosystem services.
\end{abstract}

Keywords Ecosystem services $\cdot$ Multiple purchasers $\cdot$ Negotiation $\cdot$ Payments for ecosystem services $(\mathrm{PES}) \cdot$ Simulation modelling $\cdot$ Spatial coordination

\section{Introduction}

The primary aim for many rural landowners is to grow agricultural products for sale in markets. That same land, however, has the potential to provide a wide array of non-market ecosystem goods and services (Millennium Ecosystem Assessment 2005; UK National Ecosystem Assessment 2011). Since those ecosystem services often have the characteristics of public goods, landowners have little incentive to preserve the levels of service currently provided, never mind incur costs to increase provision. Indeed, in order to deliver ecosystem services landowners will often require some form of external incentive (Kemkes et al. 2010). Mechanisms instituting such incentives, including regulation and direct payments, have seen increasing application over recent years (FAO 2007; Schomers and

Gregory Smith

g.smith4@exeter.ac.uk

1 Land, Environment, Economics and Policy Institute (LEEP), University of Exeter Business School, Xfi Building, Rennes Road, Exeter EX4 4PU, UK 
Matzdorf 2013). The particular focus of this paper is on mechanisms that can be classified as Payments for Ecosystem Services (PES) schemes. In PES schemes the landowner is compensated for the net revenues forgone by the adoption of an alternative land-management practice (Engel et al. 2008). The central motivation for this paper stems from the fact that those changes often deliver flows in more than one ecosystem service, ${ }^{1}$ flows that are often intrinsically related to location and the spatial configuration of land use (Lawton et al. 2010; Banerjee et al. 2014; Wätzold and Drechsler 2014; Natural Capital Committee 2015). What is more, the different flows of services may accrue to different beneficiary groups each of whom might be prepared to pay for improvements in those service flows through a PES scheme.

In recent years there has been a rapid increase in the number of PES schemes instituted around the world (Schomers and Matzdorf 2013). These have tended to take one of two forms. There are a number of schemes that deliver a flow of ecosystem services that benefit a broad population, for example, Costa Rica's national PES program 'Pagos por Servicios Ambientales (Sánchez-Azofeifa et al. 2007) and agri-environment schemes such as the UK's Countryside Stewardship which pays landholders to adopt wildlife-friendly land management. Furthermore, there are also numerous examples of PES schemes instituted by a single private organisation seeking a cost-effective mechanism to manage and/or protect a natural resource critical to their business activities, for example, Nestlé Water's payments to farmers to remove nitrate pollution from the source of their Vittel mineral water product (Perrot-Maître 2006) and the scheme run by the Indonesian PLTA power company which pays upstream communities to reduce deforestation activities in order to reduce sedimentation in their hydropower dam (Fauzi and Anna 2013).

One feature of all these schemes is that they are monopsonies; the PES market is created and funded through the patronage of a single purchaser. Far less common are schemes that channel payments from two or more beneficiaries, one example is the PES scheme to protect cloud forest in the Los Negros watershed of Bolivia where payments are a combination of an international biodiversity conservation donor and downstream irrigators (Asquith et al. 2008). Despite their rarity, the potential advantages of multiple-purchaser PES schemes are numerous. Most directly, by drawing in multiple sources of funding they offer the possibility of expansion of the scheme such that it delivers more substantial improvements in ecosystem service benefits or of cost-sharing, thereby reducing the financial burden on any single purchaser. Also, multiple-purchaser schemes might broaden the range of PES-funded investments potentially giving rise to opportunities for the complementary production of multiple ecosystem services. Given these benefits there has been increasing interest, particularly from the public sector, to leverage finance from multiple beneficiaries in PES schemes (LaRocco and Deal 2011; Deal et al. 2012; Defra 2013).

In this paper, we use spatial simulation modelling to study multiple-purchaser PES institutions. In those simulations there are multiple beneficiaries across the landscape with each beneficiary looking to increase the delivery of a different ecosystem service. We assume that the multiple ecosystem services are delivered by a single land-management change. We also assume that the beneficiaries' objective is to maximise their ecosystem service benefits subject to a given budget, we ignore other alternative objectives

\footnotetext{
1 A frequently cited land-management change that leads to multiple benefit flows is the planting of riparian buffers, in which strips of land along watercourses are planted with vegetation. This can improve water quality, reducing sediment, nitrate and phosphate runoff, while simultaneously sequestering carbon and providing habitat for wildlife (Salzman 2010).
} 
such as meeting an objective for least cost or profit maximising. Simulation modelling as a choice of method allows us to explore the factors that may influence optimal multiple-purchaser PES scheme design. The complex interactions between buyers and sellers and varying productivity and costs across space means analytical solutions are not possible and the lack of real world examples makes empirical data on multiple-purchaser PES scarce.

The multiple-purchaser focus of this paper differs markedly from the majority of previous studies. Others have analysed spatial patterns of land use to optimise a single ecosystem service, for example, biodiversity in the conservation biology literature (Williams et al. 2005). Likewise, authors have studied the problem of how to optimally design PES mechanisms administered by a single purchaser, for example, Polasky et al. (2014). This paper is most similar to Bode et al. (2011) who address how multiple independent organisations may organise themselves in a multiple-purchaser PES-like scheme regarding biodiversity improvements. They show that a cooperative frontier exists with the potential for Pareto improving outcomes for beneficiaries, however, they do not specify a decision making institution that could reach solutions on that frontier. Our paper takes negotiation as a potential decision making institution and we test for cases in which Pareto improvements are possible and where they are not. We compare against two other potential institutions-sequential and strategic. In both institutions the beneficiaries act independently, in the sequential institution, one beneficiary moves first without strategic consideration of the other beneficiaries and in the strategic institution the beneficiary moving first does so with strategic consideration of the other beneficiaries.

We consider three simulation environments, those simulation environments add context and realism over the Bode et al. (2011) study in three important ways. In all our simulations we allow for spatial heterogeneity in the ecosystem service benefits and costs, in the second we include spatial interdependence in the service benefits and in the third we include asymmetric information over the sellers' costs. We find that as realism is added to the simulations we see fundamental changes in how beneficiaries of ecosystem services would organise themselves.

In the next section, we introduce the key literature upon which this article builds. In Sect. 3 we set out our motivating example and build up a model that can be used to describe the spatial decision making of purchasers of ecosystem services using integer linear programmes. In Sect. 4 we build up models of multiple-purchaser decision problems and in Sect. 5 we present results from three simulation environments in which we provide insights and draw conclusions about the potential for multiple-purchaser PES schemes using comparisons of the solutions gained from the multiple-purchaser decision-making institutions.

\section{Literature Review}

Polasky et al. (2014) identify three key challenges for designing optimal PES schemes. First, a PES scheme requires coordination between multiple private sellers of ecosystem services, second, the provision of ecosystem services often depends on the spatial configuration of land-use, and third, landholders often hold private information about the cost of providing ecosystem services. Our paper incorporates those challenges, moreover, we focus on the additional complexity of coordination between multiple beneficiaries of ecosystem services on the demand-side of the market. 


\subsection{Purchasers of Ecosystem Services}

Our paper relates to the quantitative methods developed in the conservation literature, often based on mathematical programming, for selecting an optimal set of land parcels that deliver ecosystem service flows (Kirkpatrick 1983; Williams et al. 2005). In that literature the focus is most commonly on biodiversity outcomes, with an objective function typically measuring species richness or a representation of habitat requirements (Pressey et al. 1997). In a recent application, similar in spirit to our own, Armsworth et al. (2012) use methods of mathematical programming to compare the spatial configuration of farm management practice changes that deliver optimal levels of bird species richness with those that might be achieved through different simplified designs of single-purchaser PES markets. We draw on such literature and apply mathematical programming methods to explore the multiple ecosystem service/multiple-purchaser problem.

Our paper also relates to a complimentary study, Smith and Day (2018), who show, in the context of a two-purchaser PES scheme, that there always exists incentives for beneficiaries of a public good to free-ride when there is the possibility of another buyer paying for the public good. The authors go on to show that negotiation can overcome this collective action problem in a laboratory experiment. In the context of multiple-purchasers there also exists a literature related to the "stacking" of ecosystem services, this refers to the practice of a landholder receiving multiple separate payments from different purchasers as a result of delivering multiple ecosystem service improvements (Woodward 2011). However, the majority of current PES schemes either do not allow or dissuade stacking through requiring each payment to generate additionality (Salzman 2009; Woodward 2011). For this reason we exclude the possibility of stacking payments to a single landholder.

Several studies have estimated trade-offs between different ecosystem services, for example the trade-off between goods such as timber or agriculture and species conservation (Nalle et al. 2004; Polasky et al. 2005, 2008) or carbon storage and biodiversity (Nelson et al. 2008; Venter et al. 2009). In solving these problems, however, the authors assume that a single budget exists and that with this budget a single decision maker solves for efficient outcomes.

\subsection{Spatial Interdependence and Landscape Configuration}

For a number of ecosystem services the landscape pattern of land-use and conservation activities can be an important determinant of overall provision. Polasky et al. (2014) note the importance of including spatial interdependence when designing optimal policies and incentives, particularly for ecosystem services such as biodiversity. For example, Lewis et al. (2011) compare several design options for conservation schemes in the Willamette Basin, Oregon (USA) and find that accounting for spatial interdependence in the scheme design can significantly enhance cost-effectiveness.

Although the mathematical programming in the conservation literature commonly assumes spatially independent objectives, a number of studies include spatial interdependence in the objective functions (Onal and Briers 2002; Önal and Briers 2005). Other studies have included economic aspects alongside spatially interdependent ecosystem services where payments to landholders are a function of the decisions of neighbouring landholders. One particular area that is well studied is the "agglomeration bonus" (Parkhurst et al. 
2002; Parkhurst and Shogren 2007; Wätzold and Drechsler 2014) where landholders are paid a bonus when neighbouring landholders are also part of the scheme.

Finding optimal solutions with spatially interdependent benefits can be challenging as modelling spatial interdependence necessarily creates a non-linear problem, in this paper we create solutions for purchasers' objectives with spatially interdependent ecosystem services by forming a linearised version of the purchaser's decision problem.

\subsection{The Costs of Ecosystem Service Provision and Asymmetric Information}

Asymmetric information is an important feature of most PES schemes. Landholders typically have information about their costs of undertaking conservation actions which are observable to themselves but unobservable to the beneficiaries. This information asymmetry means rent-free contracts cannot be written, and is a key driver for the increasing usage of information revelation mechanisms such as conservation auctions where sellers utilise competitive bidding to reduce seller rents. The combination of spatially interdependent ecosystem services and sellers with private cost information makes solving for optimal land-use extremely difficult. However, Lewis et al. (2011) show the importance of spatial landscape patterns in the overall provision of ecosystem services and demonstrate the need for an information revelation mechanism such as an auction to achieve optimal outcomes. Polasky et al. (2014) use a variant of the Vickery-Clarke-Groves auction to incentivise truthful revelation of the sellers' costs and then optimise over the landscape in a second stage. In this paper we also use a two stage process, however, we employ an agent-based auction simulator developed in Elliott et al. (2015), and summarised in the "Appendix", to estimate sellers' bids in a discriminatory price auction. The auction simulator provides estimates of how sellers might shade their bids and we use those shaded bids as estimates of the sellers' costs in the multiple-purchaser PES scheme.

\section{Modelling Single Purchasers}

Our motivating example concerns an agricultural landscape. That landscape comprises a large number of land parcels managed by independent farmers whose current activities are determined by the objective of maximising profits from the production of food. Alternative land-management practices are possible, for farmers, however, those alternatives are costly; they may require additional expenditure or result in a lower yield of agricultural output. At the same time, alternative land-management practices can deliver ecosystem services beneficial to one or many groups. The purpose of a PES scheme is to provide the institutional framework within which beneficiaries can compensate a farmer for costly land-management change. We start in this section by formalising the problem for single purchasers before expanding to include multiple-purchasers in the next section.

For each land parcel $j$ in a landscape a farmer has a binary choice; carry on with normal production or undertake an alternative land-management practice. To maintain tractability we concentrate on the case where only one alternative land-management practice exists; to fix ideas, let us assume that that alternative is taking a land parcel out of agriculture. We use the decision variable $x_{j}$ to denote the land-use choice on each land parcel. If a farmer carries on with normal agricultural production on their parcel of land then $x_{j}=0$, however if that farmer agrees to undertake an alternative land-management practice then $x_{j}=1$, 
such that $x_{j} \in\{0,1\}$. Building on that notation we denote a landscape configuration by the vector $\boldsymbol{x}=\left[x_{1} x_{2} \ldots x_{N}\right]$.

\subsection{Benefits}

The spatial production of ecosystem services from a land management change can be thought of in terms of two key components, spatial heterogeneity and spatial interdependence (Goldman et al. 2007). Spatial heterogeneity refers to the uneven nature of service production across the landscape. For example, the production of carbon storage by planting trees is relatively spatially homogeneous, although the carbon storage potential of trees could depend on spatial characteristics such as altitude, soil type, exposure and latitude, the primary determinant is likely, in most cases, to be the amount of trees planted (Laurance et al. 2000, 2002). In contrast, the production of water quality is spatially heterogeneous, such that certain land parcels, for example, locations close to watercourses or on steep slopes, are likely to produce more benefits (Steinman and Denning 2005; Goldman et al. 2007).

Spatial interdependence, on the other hand, refers to the relationship between service productive capacity on one parcel of land and the service productive capacity of other land parcels. For example, this could be quantity interdependence, such that the aggregate abundance of a particular land use affects the benefits, or configuration interdependence, such that locating certain land-management practices close together or far apart affects the benefits (Mitchell et al. 2013). An example of configuration interdependence can be found in the creation of a large contiguous natural habitat which delivers greater biodiversity benefits than the creation of a series of separate natural habitats of the same total area (Mitchell et al. 2015). A contrasting example concerns the location of a natural site used for recreation; the closer that new site is to an already existing site offering a similar recreational experience the less benefit the additional site is likely to provide (Sen et al. 2014).

Heterogeneity and interdependence of benefit flows are captured in the following mathematical programmes. The benefits that a purchaser gains from a particular landscape configuration is denoted by the function $b(\boldsymbol{x})$. For spatially heterogeneity that function takes the simple form:

$$
b(\boldsymbol{x})=\sum_{j=1}^{N} b_{j} x_{j}
$$

where $b_{j}$ represents the benefits from land-management changes on each land parcel and spatial homogeneity is the special case where $b_{j}=b \forall j$.

For spatially interdependent ecosystem services (for example biodiversity) the structure of the benefit function becomes more complex. Indeed for biodiversity production the spatial production process is often too complex to explicitly represent in a mathematical model (Williams, ReVelle, and Levin 2005). A common alternative, and one we adopt here, is to use a proxy based on the spatial pattern of land use (Nalle et al. 2002; Polasky et al. 2005, 2008). Different desired landscape configurations call for different mathematical representations of the benefit function. Certain functions give more weight to spatial patterns where land in the PES scheme is agglomerated together or connected, other functions give more weight to spatial patterns that distribute land in the PES scheme close to features, or in a number of smaller reserves (Onal and Briers 2002; Williams and Snyder 2005; Tóth and McDill 2008). 
For a spatially interdependent ecosystem service we take a particular example from Nalle et al. (2002) which prioritises the agglomeration of land by minimising the sum of the distances between chosen land parcels:

$$
b(\boldsymbol{x})=-\sum_{j=1}^{N} \sum_{k>j} d_{j k} x_{j} x_{k}
$$

where $x_{j}$ and $x_{k}$ are pairs of land parcels and $d_{j k}$ is the distance between them. Since closely located land parcels are separated by the smallest distance $d_{j k}$ higher values for the benefit function in Eq. (2) are achieved by choosing a compact tract of adjacent land parcels. ${ }^{2}$

In the subsequent simulations we take Eq. (1) to represent spatially heterogeneous benefits and Eq. (2) to represent spatially interdependent benefits.

\subsection{Costs}

The creation of any PES scheme requires the exchange of information between buyers and sellers; one important piece of information is the cost to a farmer of adopting an alternative land-management practice. Here we begin from the assumption that the cost is already known and then go on to use an auction simulator to estimate farmers' bids in a discriminatory price auction. In both cases, each cost/bid $c_{j}$ is independent such that a purchaser's costs from a PES scheme can be represented by the following simple form:

$$
c(\boldsymbol{x})=\sum_{j=1}^{N} c_{j} x_{j}
$$

For the first two simulation environments we draw heterogeneous costs from a standard normal distribution and for the third simulation environment we test our results against a more realistic cost distribution. In that third simulation environment we utilise the Farm Business Survey which recorded the distribution of farm gross margins per hectare for 2013 in England. The data is adjusted to remove the influence of the very high returns realised in horticulture, and a sample is drawn at random from the resultant distribution. Each of those farm gross margins per hectare are taken to be the foregone income of a farm in our simulation.

\subsection{The Purchasers' Problems}

The final step in formally defining a purchaser's problem is to understand their objective. Numerous possibilities present themselves. For example, the buyers may have a profit maximising objective, alternatively they could minimise the cost of reaching a particular environment target. For the simulations in this paper we imagine purchasers looking to maximise ecosystem service benefits within the constraints of a limited budget, $M$ :

\footnotetext{
${ }^{2}$ In the conservation literature, the question of which parcels to select for changes in land management, are often made more complex by the need to ensure that those parcels provide habitat for the species that are the targets of conservation efforts. Often these are defined by a species-covering constraint that requires that the chosen set of land parcels contains one or more parcels providing habitat for each target species.
} 


$$
\begin{aligned}
& \max _{x_{j} \in \boldsymbol{x}} F(\boldsymbol{x})=b(\boldsymbol{x}) \\
& \text { s.t. } \quad G(\boldsymbol{x})=c(\boldsymbol{x})-M \leq 0
\end{aligned}
$$

A general version of the PES purchasing problem can be represented in the binary integer programme:

$$
\begin{aligned}
& \max _{x_{j} \in x} F(\boldsymbol{x}) \\
& \text { s.t. } \quad G(\boldsymbol{x}) \leq 0 \\
& \quad x_{j} \in\{0,1\}
\end{aligned}
$$

where the binary constraint $x_{j} \in\{0,1\}$ is added to the constraint set to represent the choice of whether to fund land management changes in a parcel or not.

\section{Modelling Multiple-Purchasers}

When more than one beneficiary stands to gain from land-management changes the purchaser's problem is complicated by strategic considerations; which land parcels should the purchaser fund given the possibility another beneficiary may pay for those parcels instead? Our simulations explore the impacts of such interactions given different assumptions regarding the strategic sophistication of purchasers. We focus on a case where there are only two potential buyers of ecosystem services-buyer A and buyer B. We describe a particular choice for buyer A by a vector $\boldsymbol{x}_{A}$ where element $x_{A, j}=1$ if buyer A chooses to fund land-management changes in land parcel $j$ and $x_{A, j}=0$ otherwise. The choice vector $\boldsymbol{x}_{B}$ is defined analogously for buyer B. It is important to note that the buyers' benefits are determined by different ecosystem services and that a single land-management change on a parcel of land leads to the production of two ecosystem services, one beneficial for buyer $\mathrm{A}$ and one beneficial for buyer B. As such we can denote buyer A's benefits as $b_{A}\left(\boldsymbol{x}_{\boldsymbol{A}}, \boldsymbol{x}_{\boldsymbol{B}}\right)$ and buyer B's benefits as $b_{B}\left(\boldsymbol{x}_{A}, \boldsymbol{x}_{\boldsymbol{B}}\right)$.

Subsequently we shall define maximisation problems that identify optimal funding choices for each buyer. We will denote the solutions to those problems by the vectors $\boldsymbol{x}_{A}^{*}$ and $x_{B}^{*}$. Note that the elements of the vector $x_{A}^{*}\left(x_{B}^{*}\right)$ take the value 1 for all $j$ where buyer $A$ (buyer B) funds the land-management change and 0 otherwise; this differs from $\boldsymbol{x}$, which is 1 for all parcels that have been converted across the whole landscape.

In studying the choices of buyers A and B, we consider three different contexts within which their decisions are made: in the first the buyers make their decisions sequentially; in the second the buyers make their decisions strategically so that the buyer moving first takes into account the expected response of the other buyer; in the third the buyers make their decisions strategically as the outcome of a process of negotiation. For clarity, we assume that the buyers do not face transaction costs in implementing these decision making institutions.

\subsection{Sequential Decision Making}

The first decision making problem we consider involves independent buyers making sequential non-cooperative choices. Such a situation could occur when one buyer, the 
first mover, choses to go ahead and fund changes in their most preferred land parcels. Subsequently, another buyer, the second mover choses to fund further changes. A general form representation of this decision problem is:

\begin{tabular}{llc}
\hline Buyer & Problem & $\begin{array}{l}\text { Solu- } \\
\text { tion } \\
\text { vectors }\end{array}$ \\
\hline $\begin{array}{l}\text { Buyer A } \\
\text { first mover }\end{array}$ & $\max _{x_{j} \in x} F_{A}(x)$ & $x_{A}^{*}$ \\
$\begin{array}{l}\text { Buyer B } \\
\text { second mover }\end{array}$ & s.t. $\quad G_{A}(x) \leq 0, x_{A, j} \in\{0,1\}$ & \\
& $\max _{x_{j} \in z} F_{B}(x)$ & $x_{B}^{*}$ \\
& s.t $G_{B}(x) \leq 0, x_{B, j} \in\{0,1\}$ &
\end{tabular}

In this sequential problem the second mover knows which land parcels have already been funded. We denote this in the problem by maximising over $x_{j} \in z$, where $z \subset \boldsymbol{x}$ such that $z=\left\{x_{j} \mid x_{A, j}^{*}=0\right\}$, in words, $z$ is the set of $x_{j}$ that have not been selected in the first mover's solution. Of course, in this institutional setup moving second can confer considerable advantages such that when sequential decision making is a possibility we might expect to see free riding behaviour in which buyers wait for the other buyer to move first.

\subsection{Strategic Decision Making}

The second decision making problem we consider involves strategic non-cooperative buyers. In such a situation the first mover thinks strategically about where to purchase. Importantly, the first mover knows that the second mover observes its purchases and that they then subsequently respond optimally. In game theory this type of institution is known as the Stackelberg game, and in mathematical programming as bilevel optimisation. A general form representation of this decision problem is:

\begin{tabular}{llc}
\hline Buyer & Problem & $\begin{array}{c}\text { Solu- } \\
\text { tion } \\
\text { vectors }\end{array}$ \\
\hline $\begin{array}{l}\text { Buyer A } \\
\text { first mover }\end{array}$ & $\max _{x_{j} \in x, y_{j} \in y} F_{A}(x, y)$ & $x_{A}^{*}$ \\
& s.t. $G_{A}(x, y) \leq 0, x_{A, j} \in\{0,1\}$ & \\
$y \in \arg _{z \in y}\left\{F_{B}(x, z): G_{B}(x, z) \leq 0\right\}$ & \\
Buyer B & $\max _{x_{j} \in z} F_{B}(x)$ & $x_{B}^{*}$ \\
second mover & s.t $G_{B}(x) \leq 0, x_{B, j} \in\{0,1\}$ & \\
& &
\end{tabular}

In the strategic problem the first mover solves their maximisation problem whilst anticipating the response of the second mover, we denote the response of the second mover as $y$. As such the second mover's problem is nested inside the first mover's problem. For the second mover their problem is identical to the second mover in the sequential institution as they maximise over the sites not chosen by the first buyer. 
In this strategic institutional setup moving first can confer considerable advantages such that the buyer can strategically choose so as to maximise their objective knowing what the other buyer will subsequently choose.

\subsection{Negotiated Decision Making}

Things get more complex when we imagine a situation in which buyers decide which land parcels each will fund through a process of negotiation followed by binding agreement. To explore negotiated outcomes we consider a model of strategic non-cooperative bargaining suggested by Rubinstein's alternating bargaining theory (Rubinstein 1982). In that model, bargaining proceeds via a structured game in which players make alternate offers to one another regarding the set of land parcels to be funded through the PES scheme. If an offer is accepted then agreement is reached. Alternatively, an offer can be rejected in which case the rejecter is given the option of making a counter-offer. Rejecting an offer and making a counter-offer, however, comes at a cost-often justified as the costs of delay.

In our simulation of negotiations we assume all decisions are made with perfect information regarding the purchasing preferences of the other buyer. Furthermore, we assume that delay costs are the same for each buyer. In any single round of negotiation, one of the purchasers, for the sake of illustration purchaser A, makes a proposal as to which land parcels they will fund themselves. In each round we assume that the proposing purchaser is seeking to maximise their own objective function, $F_{A}(\boldsymbol{x}, d)$, subject to their own constraint set $G_{A}(x, d) \leq 0$. Of course, to ensure that the proposal will not be immediately rejected by the other purchaser it must also be the case that the proposal also conforms to the second purchaser's constraint set $G_{B}(\boldsymbol{x}, d) \leq 0$.

In the simplest case, where there is only one round of negotiation, we have a simple ultimatum game. The general form of a solution to this problem is given by:

\begin{tabular}{lll}
\hline Buyer & Problem & Solution vectors \\
\hline Buyer A & $\max _{x_{A, j}, x_{B, j} \in X} F_{A}(\boldsymbol{x})$ & $\boldsymbol{x}_{A}^{*}, \boldsymbol{x}_{B}^{*}$ \\
makes only proposal & s.t. $\quad G_{A}(\boldsymbol{x}) \leq 0, G_{B}(\boldsymbol{x}) \leq 0$ & \\
& $x_{A, j} \in\{0,1\}, x_{B, j} \in\{0,1\}$ & \\
\hline
\end{tabular}

Of course, no rational agent would commit themselves to a negotiation in which they simply had to accept or reject the proposal of the other purchaser. Rather we envisage a negotiation that proceeds over several, perhaps infinite rounds of proposal and counter-proposal. To solve the game over $D$ rounds of negotiation we use backwards induction. Starting in the final round we find the solution that optimises the benefits realised by the buyer proffering the final proposal. By that stage of the negotiation, the buyers will have endured delay costs. Rubinstein's solution method then moves back one round of negotiation so that $d=D-1$ and the buyer that was previously the proposer becomes the responder and vice versa. To avoid their offer being rejected, however, the new proposer must choose a pattern of land-use change that ensures that the responder receives at least as much benefit as they realised in the previous solution. Following that logic back up through the rounds of negotiation we solve for the sub-game perfect equilibrium, the offer made by the proposer in the first round of negotiation that will be immediately accepted by the responder.

In the context of our two PES buyers, negotiation for round $d$ can be represented by the following decision problem: 


\begin{tabular}{lll}
\hline Buyer & Problem & Solution vectors \\
\hline Buyer A & $\max _{A_{A, j}, x_{B, j} \in X} F_{A}(x ; d)$ & $\boldsymbol{x}_{A, d}^{*}, x_{B, d}^{*}$ \\
is the proposer in round $d$ & s.t. $\quad F_{B}(\boldsymbol{x} ; d) \geq F_{B}(\boldsymbol{x} ; d+1)$ & \\
& $G_{A}(\boldsymbol{x}) \leq 0, \quad G_{B}(\boldsymbol{x}) \leq 0$ & \\
& $x_{A, j} \in\{0,1\}, \quad x_{B, j} \in\{0,1\}$ & \\
\hline
\end{tabular}

where $F_{A}(\boldsymbol{x} ; d)$ and $F_{B}(\boldsymbol{x} ; d)$ represent the objective function of buyer A and buyer B respectively for round $d$ of negotiation and $G_{A}(x ; d)$ and $G_{B}(x ; d)$ represent the constraint set of buyer $\mathrm{A}$ and buyer $\mathrm{B}$ in round $d$ respectively.

In our analysis, we explore how different numbers of rounds of costly negotiation affect bargaining outcomes. In addition, we alternate the buyer moving first.

\section{Results}

\subsection{Simulation 1: Spatial Heterogeneity}

In our first simulation exercise we explore outcomes when the ecosystem service benefits are spatially heterogeneous but do not exhibit spatial interdependence. This simulation focuses on understanding the outcome of multiple-purchaser PES scheme under different assumptions regarding the level of correlation in the two buyer's benefits across land parcels. If that correlation is positive, then both buyers will be motivated to invest in changes in similar land parcels through the PES scheme, if it is negative then the two buyers will target land-management changes in different land parcels.

Our simulation environment was developed in MATLAB R2013a and used the solver CPLEX 12.5.1 to identify optimal solutions to the integer-linear programmes. We created a simulation environment consisting of 100 square land parcels of equal size arranged on a $10 \times 10$ grid. ${ }^{3}$ In each land parcel $j$ some form of agricultural production is taking place. We assume a single land-management change on a land parcel produces improvements in flows of two ecosystem services; one is beneficial for buyer A and the other is beneficial for buyer B. Costs are simulated using random draws from the normal distribution and the benefits to each buyer are simulated using random draws from the standard bivariate normal distribution ${ }^{4}$ with correlation coefficient $r$. As well as differences in the correlation of ecosystem service flows, we examine differences in solutions across different PES decision making institutions.

Figure 1 illustrates the benefits that accrue to the buyers under the different decision making institutions from one example simulation run. The sequential solutions (one with buyer A moving first and one with buyer B moving first) are represented by the black and grey diamonds. The strategic solutions (again one with buyer A moving first and one with

\footnotetext{
3 We use square land parcels although it should be noted that the same methodology can be applied to other geometric designs and sizes.

4 The correlated benefits are simulated using two random draws from the standard normal distribution to create two vectors of benefits $\boldsymbol{b}_{x}$ and $\boldsymbol{b}_{z}$, following this we define a third vector, $\boldsymbol{b}_{y}=r \boldsymbol{b}_{x}+\sqrt{1-\boldsymbol{b}_{x}^{2} \boldsymbol{b}_{z}}$, where $\boldsymbol{b}_{y}$ is also standard normal and $r$ is the correlation coefficient between the vectors $\boldsymbol{b}_{x}$ and $\boldsymbol{b}_{y}$. The benefits for buyer A are the vector $\boldsymbol{b}_{x}$ and for buyer B the vector $\boldsymbol{b}_{y}$.
} 


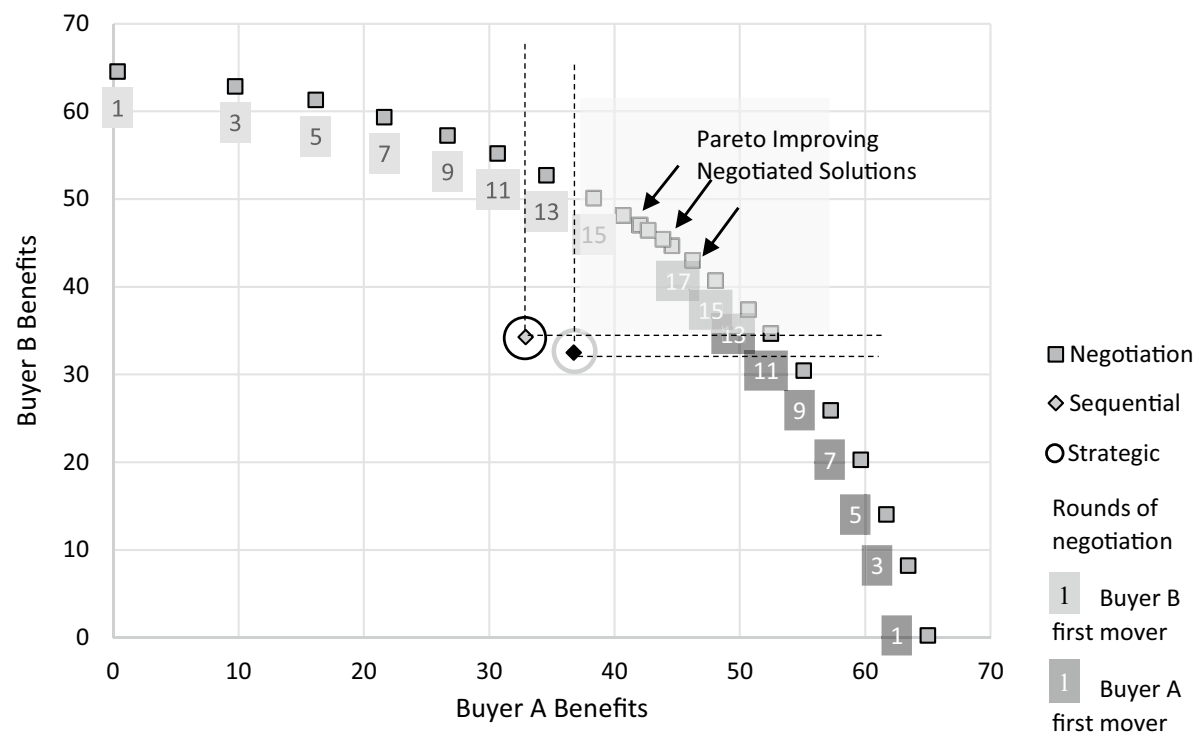

Fig. 1 Outcomes for different PES institutions, negotiated, sequential and strategic, at a correlation coefficient of 0

buyer B moving first) are represented by the black and grey circles. The negotiated solutions are represented by the numerous grey squares with the numbers showing the number of rounds of negotiation. The space where Pareto improving solutions can occur is shaded grey and the negotiated solutions which lie in the Pareto improving zone are noted.

First observe the negotiated solutions, with just one round of negotiation the outcomes are at the extremes, with the vast majority of the benefits going to the buyer who proposes the deal. As the rounds of negotiation increase the other buyer is able to negotiate a larger share, indeed after several rounds of negotiation the solutions begin to converge. As Rubinstein (1982) proved, with perfect information each negotiation has a unique subgame perfect equilibrium which is reached immediately, since it is reached immediately no resources are lost to delay and the solution is therefore efficient. Hence, for two budget constrained buyers the range of negotiated solutions lie on the efficient production possibilities frontier, a construction which identifies the levels of ecosystem services that might be delivered in a landscape and describes the nature of trade-offs across the different ecosystem service benefits (Nalle et al. 2004; Kline and Mazzotta 2012). Bode et al. (2011) use a cooperative institution, where the buyers combine their budgets, this matches the production possibilities frontier. Our simulation expands that analysis by showing that buyers of ecosystem services can reach those efficient outcomes through the process of negotiation. Indeed, we are able to show the sub-game perfect equilibriums which would be reached.

Observe that the solutions for the strategic and sequential institutions solve such that the advantage goes to the first mover in the strategic institution and the advantage goes to the second mover in the sequential institution. For the sequential institution, the second mover can observe the first mover's choices and avoid paying for those land parcels since the second buyer will receive the ecosystems benefits regardless of who contributes the money. For the strategic institution the assumption of perfect information means that the first mover knows not only their best land parcels but also the best land parcels of the other 
Table 1 Summary of the benefits from multiple-purchaser institutions from the heterogeneous benefits simulation

\begin{tabular}{|c|c|c|c|c|c|c|c|c|c|c|c|}
\hline \multirow[b]{3}{*}{ Buyer } & \multicolumn{4}{|c|}{ Sequential } & \multicolumn{4}{|c|}{ Strategic } & \multirow{2}{*}{\multicolumn{2}{|c|}{ Negotiation }} & \multirow{3}{*}{$\begin{array}{l}\text { Pareto improvement } \\
\text { potential from negotia- } \\
\text { tion }\end{array}$} \\
\hline & \multicolumn{2}{|c|}{$\begin{array}{l}\text { First mover } \\
\text { A }\end{array}$} & \multicolumn{2}{|c|}{$\begin{array}{l}\text { First mover } \\
\text { B }\end{array}$} & \multicolumn{2}{|c|}{$\begin{array}{l}\text { First mover } \\
\text { A }\end{array}$} & \multicolumn{2}{|c|}{$\begin{array}{l}\text { First mover } \\
\text { B }\end{array}$} & & & \\
\hline & A & B & $\mathrm{A}$ & B & $\mathrm{A}$ & B & A & B & A & B & \\
\hline $\operatorname{Mean}^{\mathrm{a}}$ & 0.76 & 0.94 & 0.93 & 0.77 & 0.93 & 0.77 & 0.76 & 0.94 & 1.00 & 1.00 & $83 \%$ \\
\hline Median $^{\mathrm{a}}$ & 0.76 & 0.98 & 0.92 & 0.80 & 0.92 & 0.80 & 0.76 & 0.98 & 1.00 & 1.00 & \\
\hline
\end{tabular}

${ }^{a}$ For clarity and ease of comparison the benefits have been standardised to the negotiated subgame-perfect equilibrium solution

buyer, this means they can calculate where the second mover will purchase and avoid paying for those land parcels. ${ }^{5}$ In addition, since the benefits are independent in this first simulation, we also observe that the strategic solution with buyer $\mathrm{A}$ as the first mover equals the sequential solution with buyer $\mathrm{A}$ as the second mover. The independence of the benefits means that the buyers cannot influence the spatial decision of the other purchaser, we go on to explore this further when we introduce spatial interdependence in the next simulation.

Finally let us quantify the comparison between the negotiated solutions with those that might arise from sequential or strategic decision making. Observe in Fig. 1 that the strategic and sequential solutions lie below the range of negotiated solutions. Whenever the sequential or strategic solution are below the frontier of negotiated solutions there is potential for at least one of the buyers to reach a better outcome through negotiation, however, for negotiation to be mutually beneficial both buyers would need to reach a better outcome. We explore 100 simulations and test for the existence of these Pareto improving outcomes, the results are summarised in Table 1.

In Table 1 the benefits are standardised to the negotiated subgame-perfect equilibrium solution. To calculate a single negotiated solution we use the subgame-perfect equilibrium under a scenario with a large number of rounds of negotiation when each buyer has the opportunity to be the leader and then average those two solutions. The simulations summarised in the table allow us to draw a number of interesting insights. For example, we are able to estimate the magnitude of the second mover advantage in the sequential institution and the first mover advantage in the strategic institution as an increase of approximately $16-18 \%$ points. In addition, the potential benefits from a negotiated solution are an additional 6-7\% points over being the advantaged buyer in either the sequential or strategic institutions. The final column of Table 1 shows the percentage of the simulations where there exists potential for negotiation to achieve Pareto improving outcomes, for this simulation environment with heterogeneous but spatially independent benefits the percentage is $83 \%$ of simulations. That result suggests that negotiation between buyers of ecosystem services can often lead to outcomes that are better for both buyers, indeed, those negotiated outcomes are better than either buyer could have achieved through strategically optimising their purchases or through free-riding on another buyer's investment.

\footnotetext{
${ }^{5}$ Note that for this to hold the strategic first mover also needs to know that the second mover will definitely participate.
} 
One can see from the fact that Pareto improvements were possible in only $83 \%$ of the simulations that negotiation does not always lead to Pareto improvements. To understand the reasons for this we run a series of simulations in which we vary the correlation between the ecosystem service benefits and a further series of simulations in which the total budget is varied. The results of those simulations are presented in Tables 2 and 3.

Observe the first four columns of Table 2 when the correlation between the ecosystem benefits is negative, at those negative correlation coefficients we see that negotiation is often Pareto improving compared to the sequential or strategic institutions. As the correlation is increased the potential for Pareto improving negotiation diminishes as shown in the final four columns of the table. To understand the reasons for this pattern first imagine negatively correlated benefits, under that situation the land parcels offering high benefits to one buyer are likely to provide low benefits to the other buyer. The opportunities for negotiation are therefore substantial as the buyers can cooperate to avoid land parcels that provide little benefits to the other. These opportunities for mutually advantageous negotiation diminish as the correlation increases because the buyers favour land parcels that are likely to be beneficial to both buyers and so even under sequential or strategic institutions the buyers reach solutions similar to those that would be negotiated.

Now observe Table 3 which shows the results of a series of simulations when the buyers' budgets are varied to allow them to purchase a certain proportion of the land parcels available in a landscape. Observe that when the buyers can pay for alternative landmanagement changes on a large proportion of the landscape the opportunities for Pareto improving negotiation diminish. With high budgets the number of land parcels not chosen reduces such that there are less opportunities for negotiation. For negotiation to be optimal there must be land parcels that provide more total benefits than the land parcels chosen independently under sequential or strategic institutions and as this choice-space reduces so too does the opportunity for Pareto improving negotiation.

\subsection{Simulation 2: Spatial Interdependence}

Our second simulation environment explores outcomes under conditions of spatial interdependence. By introducing spatial interdependence into benefits we necessarily create a non-linear decision problem for the buyer. To solve we form a linearised version of the buyer's decision problem.

In this second simulation environment, we continue to explore the two-buyer case. One buyer resembles the buyers described in simulation 1. In contrast, the second buyer's benefits depend on spatial interdependence, specifically the connectedness of the land parcels brought under alternative land-management practices. To fix ideas, we imagine that the first buyer is interested in water quality improvements (water quality buyer) that are best delivered by changing the management of land parcels near to a river while the second buyer is interested in biodiversity improvements (biodiversity buyer) with the objective of creating large/well-connected reserves, that is, contiguous land parcels taken out of agricultural production. We again create a simulation environment consisting of 100 parcels of equal size arranged on a $10 \times 10$ grid and imagine that landscape is traversed by a river.

For the biodiversity buyer we use the objective function outlined in Eq. (2) where the sum of the distances between selected land parcels are minimised. To enable that quadratic objective function to be included in our linear-programming framework we use the method proposed by Onal and Briers (2002) to linearise the problem through the introduction of two new constraints: 


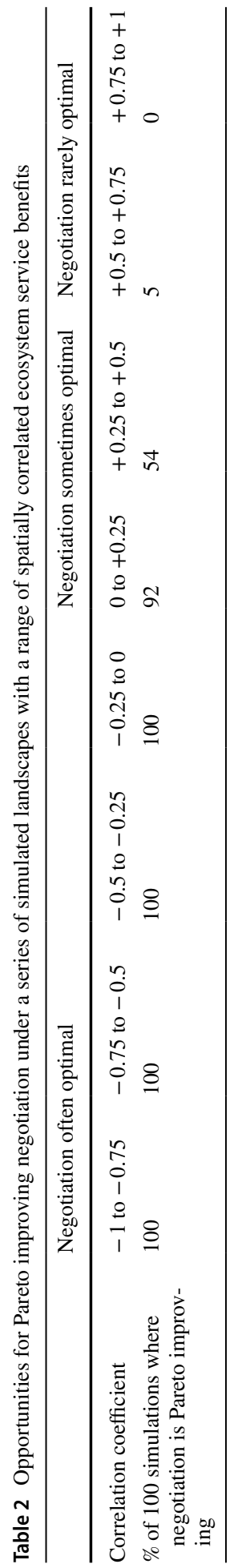


Table 3 Opportunities for Pareto improving negotiation under a series of simulated landscapes with a range of buyers' budgets

Negotiation sometimes optimal

mal

\begin{tabular}{llllll}
\hline $\begin{array}{l}\text { Proportion of all land } \\
\text { parcels purchased with } \\
\text { combined budget }\end{array}$ & $0-10 \%$ & $10-25 \%$ & $25-50 \%$ & $50-75 \%$ & $75-100 \%$ \\
$\begin{array}{l}\% \text { of } 100 \text { simulations } \\
\text { where negotiation is }\end{array}$ & 58 & 42 & 24 & 20 & 6 \\
Pareto improving $^{\mathrm{a}}$ & & & & \\
\hline
\end{tabular}

${ }^{\mathrm{a}}$ These results are for simulations with a correlation coefficient of 0.5 , note that the percentages would change for other correlations as outlined above, but the overall pattern remains

$$
\begin{aligned}
& \min _{x} \sum_{j \in J} \sum_{k>j} d_{j k} u_{j k} \\
& \text { s.t. } \quad u_{j k} \leq x_{j} \\
& u_{j k} \leq x_{k} \quad \forall j \in J, \forall k \in D_{j}, k>j
\end{aligned}
$$

where $u_{j k} \in\{0,1\}$; being 1 if land parcels $j$ and $k$ are both selected and 0 otherwise. The two constraints enforce this definition of the binary $u_{j k}$ variables, for example, if $u_{j k}$ is 1 then the constraints imply that both $x_{j}$ and $x_{k}$ must be greater than or equal to 1 and since they are also binary variables that implies both have to equal 1 . To convert to a maximisation problem we maximise the inverse of the distances, $d_{j k}$ and add a budget constraint:

$$
\begin{aligned}
& \operatorname{Max} \sum_{j \in J} \sum_{k>j}\left(\frac{1}{d_{j k}}\right) u_{j k} \\
& \text { s.t. } \quad u_{j k} \leq x_{j} \\
& u_{j k} \leq x_{k} \quad \forall j \in J, \quad \forall k \in D_{j}, k>j \\
& \sum_{j} c x_{j}-M \leq 0
\end{aligned}
$$

To understand the difference between the first simulation with spatially heterogeneous but independent benefits and this simulation where one buyer's benefits are spatially interdependent we plot an analogous example to that in Fig. 1 here in Fig. 2. Observe that the negotiated solutions again form a frontier dependent on the number of rounds of negotiation. For the strategic and sequential solutions, unlike Fig. 1, we now see divergence between the two institutions. In particular, when the first mover is the water quality buyer in the strategic institution that buyer can use the first mover advantage to influence the choices of the second mover, the biodiversity buyer. For our example, the water quality buyer can choose land parcels to purchase strategically that would make it in the best interest of the biodiversity buyer to purchase land parcels close to the river. In other words, the water quality buyer can use the fact that the biodiversity buyer's benefits are spatially 


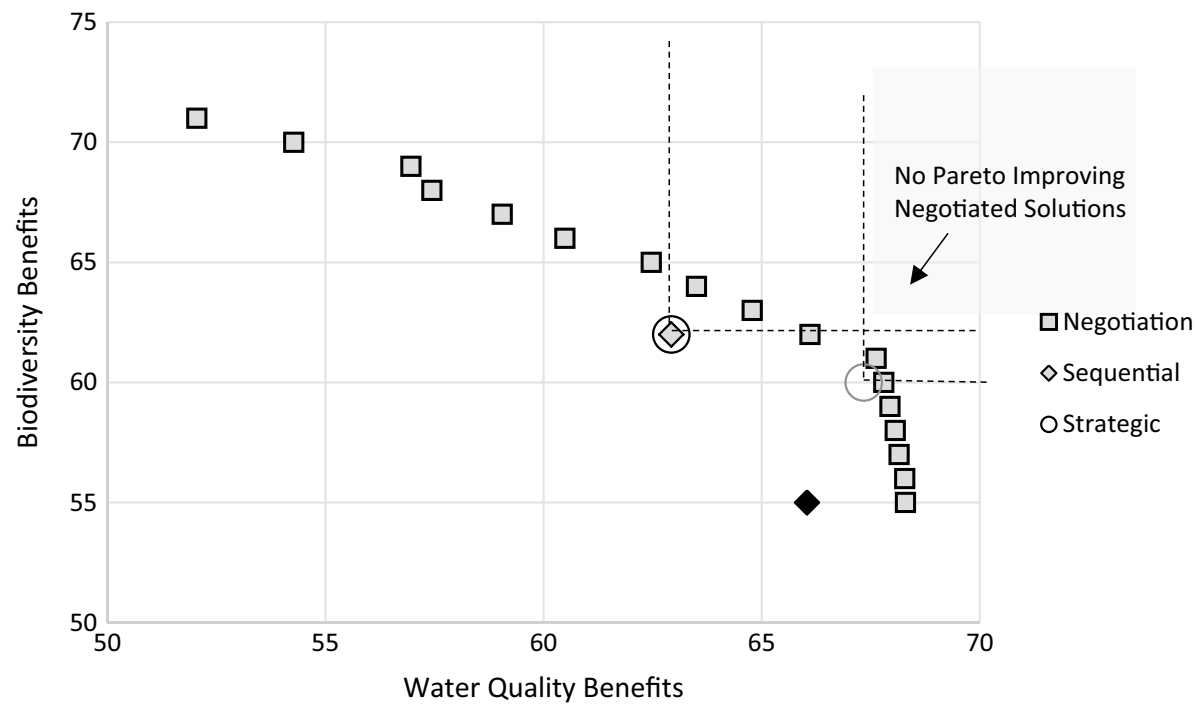

Fig. 2 Outcomes for different PES institutions, negotiated, sequential and strategic when one buyer benefits from spatially interdependent ecosystem services

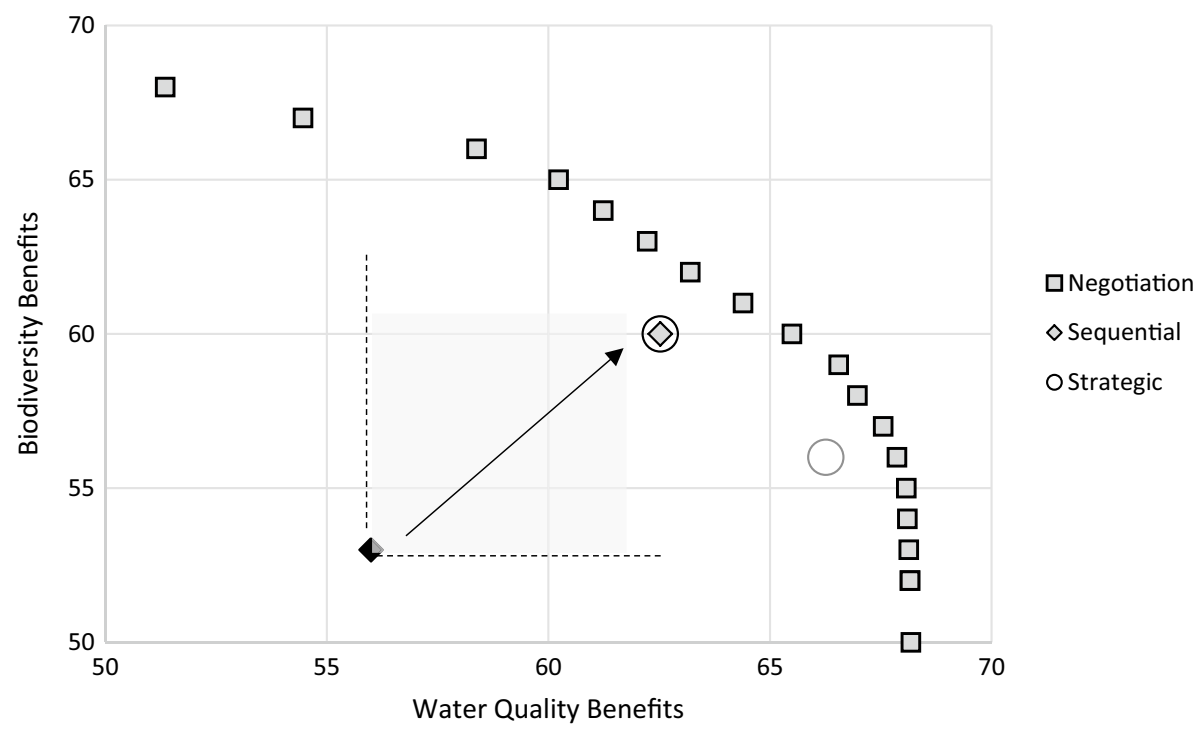

Fig. 3 Outcomes for different PES institutions, negotiated, sequential and strategic when one buyer benefits from spatially interdependent ecosystem services

interdependent to strategically maximise their own benefits. Observe also that the same advantage is not available to the biodiversity buyer, they cannot influence the water quality buyer's choice because the water quality buyer's benefits are independent of spatial configuration. As with the first simulation environment, even thinking strategically, the best 
Table 4 Summary of the benefits from multiple-purchaser institutions from the spatially interdependent benefits simulation

\begin{tabular}{|c|c|c|c|c|c|c|c|c|c|c|c|}
\hline \multirow[t]{3}{*}{ Buyer } & \multicolumn{4}{|c|}{ Sequential } & \multicolumn{4}{|c|}{ Strategic } & \multirow{2}{*}{\multicolumn{2}{|c|}{ Negotiation }} & \multirow{3}{*}{$\begin{array}{l}\text { Pareto improvement } \\
\text { potential from negotia- } \\
\text { tion }\end{array}$} \\
\hline & \multicolumn{2}{|c|}{$\begin{array}{l}\text { First mover } \\
\text { Bio }\end{array}$} & \multicolumn{2}{|c|}{$\begin{array}{l}\text { First mover } \\
\text { Water }\end{array}$} & \multicolumn{2}{|c|}{$\begin{array}{l}\text { First mover } \\
\text { Water }\end{array}$} & \multicolumn{2}{|c|}{$\begin{array}{l}\text { First mover } \\
\text { Bio }\end{array}$} & & & \\
\hline & Wat & Bio & Wat & Bio & Wat & Bio & Wat & Bio & Wat & Bio & \\
\hline Mean $^{a}$ & 0.97 & 0.90 & 0.97 & 1.00 & 1.02 & 0.94 & 0.97 & 1.00 & 1.00 & 1.00 & $6 \%$ \\
\hline Median $^{\mathrm{a}}$ & 0.98 & 0.90 & 0.97 & 1.00 & 1.02 & 0.94 & 0.97 & 1.00 & 1.00 & 1.00 & \\
\hline
\end{tabular}

${ }^{a}$ For clarity and ease of comparison the benefits have been standardised to the negotiated subgame-perfect equilibrium solution

the biodiversity buyer can do is spend their budget on the best sites for them, again this coincides with the sequential solution where the biodiversity buyer moves second.

This simulation environment also reveals a further interesting result which is illustrated in Fig. 3. With one buyer whose benefits are spatially interdependent it is possible, in certain situations, to achieve Pareto improvements merely from who moves second in the sequential institution. To explain, imagine a situation in which the biodiversity buyer moves first, their incentives ensure that their aim is to create a connected area of land parcels that are converted from agriculture, however, they do not have a preference about whether that reserve is close to the river or far away from it. If it is in the best interest of the biodiversity buyer to purchase sites away from the river (because it provides the most benefit for the budget) they will do so since they are not considering the prospect of the water quality buyer also purchasing land parcels in the future. When the water quality buyer then purchases land parcels they will likely be close to the river and therefore far away from the reserve created by the biodiversity buyer. In the alternative scenario in which the water quality buyer moves first they will again purchase land parcels close to the river, however, the biodiversity buyer, moving second, can see the water quality buyer choices and take advantage of them to create a large contiguous reserve. That configuration of land parcels has the potential to simultaneously provide connected land parcels (beneficial for biodiversity) and land parcels close to the river (beneficial for water quality) and leads to the potential for Pareto improvements from the biodiversity buyer moving second in the sequential institution.

Finally for the second simulation environment let us compare the outcomes from a negotiated solution with those that might arise from sequential and strategic decision making. We explore 100 simulations and test for the existence of these Pareto improving outcomes, the results are summarised in Table 4.

To ensure comparability all values are again standardised against the negotiated outcome. The first thing to note is evidence of the aforementioned Pareto improvements from who moves first in the sequential institution. Over all 100 simulations we see that when the water quality buyer moves first they do just as well on average as when it is the second mover and the biodiversity buyer does substantially better. Indeed in $43 \%$ of the simulations we see evidence of Pareto improvements from the water quality buyer moving first in the sequential institution. A further key result is that the sequential and strategic solutions are on average much closer to the negotiated solution. The benefits from the sequential and strategic solutions in this simulation with spatially interdependent ecosystem services now 
range from 0.90 to 1.02 compared to the first simulation in which they ranged from 0.76 to 0.94 . Moreover, the strategic solutions in which the buyer is advantaged by moving first show that on average that buyer does better through the strategic institution than through negotiation with the other buyer. The final column shows this clearly where only $6 \%$ of the simulations provide the opportunity for Pareto improving negotiation. This is a significant result which shows that the advantages from negotiation present in the first simulation and in Bode et al. (2011) can disappear when spatially interdependent ecosystem services are introduced.

In this simulation the buyers are able to reach solutions that are closer to the negotiated frontier of solutions because the water quality buyer can influence where the biodiversity buyer chooses to purchase through its strategic choice. This leads to solutions that are both close to the river and also create a large connected area suitable for high levels of biodiversity, solutions similar to those reached under negotiation and therefore leaving less opportunity for negotiated solutions to be Pareto improving.

\subsection{Simulation 3: Cost Uncertainty}

In our third simulation environment we remove the assumption that the costs are known exactly to the buyers. Buyers can employ a number of mechanisms to encourage sellers to reveal their true costs, for example, Vickrey-Clarke-Groves auctions where bidders maximise their expected utility by bidding in the auction at the value of their true costs. These types of auctions have been studied theoretically but are rare in practice. Indeed, when conservation auctions have been implemented in real-world schemes they have tended to use discriminatory price auctions (Stoneham et al. 2003; Schilizzi and Latacz-Lohmann 2012; Day and Couldrick 2013). We therefore employ a discriminatory-price auction simulator, developed in Elliott et al. (2015) and summarised in the "Appendix", to estimate the sellers' bids in a conservation auction. For the sellers' costs we utilise the Farm Business Survey that recorded the distribution of farm gross margins per hectare for 2013 in England. Each of those farm gross margins per hectare are taken to be the foregone income of a farm in our simulation. We continue to explore the two-buyer case and start by illustrating an example similar to the first simulation with spatial heterogeneity but no spatial interdependence, the results are shown in Panel A of Table 5 for three simulations: (1) the first, where the costs to the buyers are equivalent to true costs, (2) the second where the costs are bids from an auction without transaction costs (and therefore with full participation from the sellers), (3) and the third where costs are bids from an auction with transaction costs (and therefore without full participation from the sellers).

The true costs row of Panel A shows that with realistic costs the results are qualitatively equivalent to the results observed in the first simulation environment, with spatial heterogeneity in the ecosystem services but without spatial interdependence there are lots of opportunities for Pareto improving negotiation. These results continue in the other two simulations where the buyers' costs are from auction bids, however, note two important differences. Firstly, the cost efficiency of the PES scheme, here defined as the ecosystem benefits divided by the costs, declines when the costs to the buyers are bids from the auctions. This occurs as the sellers are able to claim rents. When transaction costs are included in the auction the sellers increase their bids to recoup those transaction costs or choose not to participate. These actions again cause the efficiency of the PES scheme to fall. In addition, the lack of participation leads to the buyers paying for land-management changes on a 


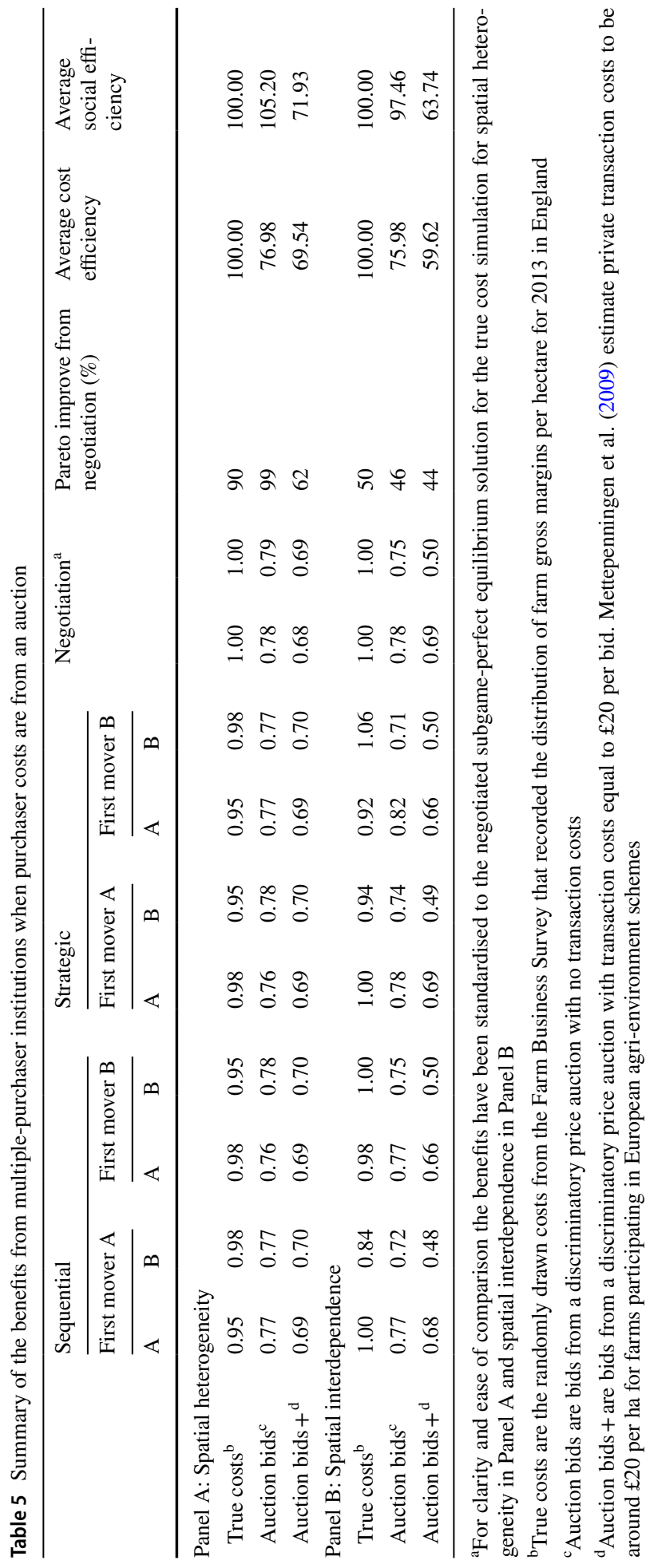


higher proportion of the landscape and as we showed in simulation 1 this reduces opportunities for Pareto improvement through negotiation.

Finally we explore the effect of uncertain costs when the benefits are spatially interdependent, results are shown in Panel B of Table 5. Once again we observe similar patterns to the earlier simulations, there are less opportunities for negotiation to be Pareto improving when spatial interdependence is introduced, on average the strategic institution does as well or better than negotiation and we see additional evidence of the potential for Pareto improvements from the water quality buyer moving first in the sequential institution.

The auction simulator enables us to assess the efficiency of the PES scheme when the sellers bid using realistic bidding patterns. Observe the final two columns of the table, as we have seen panel A shows the cost efficiency reducing when the costs are from auction bids rather than true costs, and reducing further when the sellers face transaction costs for bidding in the auction. For Panel B with spatial interdependence this pattern is even more marked, particularly when transaction costs are included. The efficiency of the PES scheme drops to 59.62. Looking across, the reason for the reduction in efficiency becomes clear, the benefits the biodiversity buyer gains in the simulation with transaction costs are substantially lower. The biodiversity buyer cannot achieve high benefits because they cannot create the same level of contiguity when some landholders do not participate.

The final column of the table shows the social efficiency of the schemes, to calculate this we divide the benefits by the social costs, where the social costs are the sum of opportunity costs foregone by farmers plus the sum of transaction costs of all those that bid in the auction. In Panel A we see that the social efficiency increases between the simulation with true costs and the simulation with auction bids, however, the opposite pattern is true for Panel B when the benefits are spatially interdependent. In both simulations, the benefits and the social costs fall with auction bids since part of the buyers budget is spent on a transfer of money to the farmers to cover their bid shading. With spatial heterogeneity the social costs fall by more than the benefits and with spatial interdependence the benefits fall by more, this can be attributed largely to the fall in biodiversity benefits. The final row shows that the addition of transaction costs into the auction causes a substantial drop in social efficiency as the transaction costs incurred by the farmers are a cost to society.

\section{Conclusion}

This paper explores the design of optimal multiple-purchaser PES schemes when a single land-management change leads to multiple benefits. It has been shown in the literature (Bode et al. 2011) that cooperation between multiple beneficiaries can lead to Pareto improving outcomes for those beneficiaries. Bode et al. (2011) show under the assumption of spatially independent ecosystem services that a Pareto improving cooperative frontier exists, however, they do not specify a decision making institution to reach solutions on that frontier. In this paper, we examine negotiation as a possible institution in which beneficiaries could come together to reach those Pareto improving outcomes. We show through spatial simulation modelling that it is possible for negotiation to lead to Pareto improvements when compared to solutions reached through non-cooperative strategic institutions; however, this result only holds under certain conditions. In particular, the spatial correlation and spatial interdependence of benefits are key in determining whether cooperation between beneficiaries is optimal and therefore if policy makers and designers of PES schemes should be prioritising bringing together beneficiaries of ecosystem services. 
Our simulations show that at negative or low positive spatial correlation between the ecosystem services benefits that negotiation is often optimal, however, these opportunities diminish as spatial correlation increases. The policy implications for this are important as it means there may be numerous occasions where it would not be in the best interest of a beneficiary to join a negotiated multiple-purchaser PES scheme and they could instead realise a better outcome through free riding on others investment as happens in our sequential institution, or through strategically deciding where to invest independently as happens in our strategic institution. Nevertheless, for the ecosystem services we consider in the second simulation, biodiversity and water quality, the evidence suggests weak positive correlations are fairly likely (Maes et al. 2012). Chan et al. (2006) provide evidence that such correlations between ecosystem services are likely to be in the range of -0.3 to +0.3 . Although such levels of spatial correlation implies advantages may be available through negotiation it is important for those thinking of designing multiple-purchaser PES schemes to consider the spatial correlation in ecosystem services carefully prior to implementation.

Our second simulation environment introduces spatial interdependence, where the benefits derived from one location are dependent on the actions in another location, such that the purchaser's problem is non-linear. We see that the advantages from negotiation/cooperation present in the first simulation and in Bode et al. (2011) diminish when spatially interdependent ecosystem services are introduced. As landscape configuration can often be important for realising ecosystem service benefits, particularly for ecosystem services such as biodiversity, policy makers need to be aware that this can fundamentally change the problem of designing optimal PES schemes. Excluding the spatial interdependence of ecosystem services when attempting to design optimal PES schemes could lead to outcomes which could potentially be far from optimal.

Our third simulation environment introduces realism into the costs that purchasers might have to pay for land-management changes by simulating farmers' bids in a discriminatory price auction. Here we show that the costs purchasers have to pay can have serious implications for designing optimal multiple-purchaser PES schemes as bids may be substantially above true costs or farmers may choose not to bid at all. This can lead beneficiaries to different optimal strategies and also has implications for the efficiency of the PES scheme as a whole. In particular, we see substantial efficiency declines for the biodiversity beneficiary.

To provide clear results, the simulations in this paper make a number of simplifications. First, all of our simulations assume that a single land-management change leads to multiple benefits. Of course this scenario is not universal, however, policy-makers or designers of PES schemes may be more likely to look to involve multiple purchasers when multiple benefits are produced, the increased interest from the public sector in multiple-purchaser PES provides evidence towards this (LaRocco and Deal 2011; Deal et al. 2012; Defra 2013). Second, all the results are for just two ecosystem service beneficiaries and caution should be exercised when applying this paper's findings to PES schemes with more than two. One can easily imagine that negotiation between large numbers of beneficiaries could lead to substantial transaction costs. Finally, although our paper explores the asymmetry in information for the sellers' costs, by introducing an auction simulator, we do not look at other forms of asymmetric information. For example, we assume the buyers have full information about the other buyers' costs and benefits, allowing them to exactly calculate the other buyer's optimal moves, relaxing this assumption would be an interesting avenue for future research.

Open Access This article is distributed under the terms of the Creative Commons Attribution 4.0 International License (http://creativecommons.org/licenses/by/4.0/), which permits unrestricted use, distribution, 
and reproduction in any medium, provided you give appropriate credit to the original author(s) and the source, provide a link to the Creative Commons license, and indicate if changes were made.

\section{Appendix}

This appendix provides a description of the agent-based auction simulator used in this paper, a full description of the auction simulator is available in Elliott et al. (2015).

The auction simulator attempts to replicate the behaviour of multiple interacting landholders when participating in a mechanism allocating contracts for pro-environmental behaviour. The agent-based simulator consists of a series of subprograms, each representing a unique individual landholder with their own unique farm.

Farmers are assumed to be rational decision makers; that is to say, each farmer, within the bounds of the information provided to them and the amount of effort they are prepared to put into figuring out how to bid, attempts to make choices which maximise their returns. A utility function, $u(c)$, which gives the utility that a farmer gets in the event that they earn an income of $c$. Moreover, we assume that farmers exhibit risk aversion and make the standard assumption that the farmer's utility function can be approximated by the Constant Relative Risk Aversion (CRRA) specification:

$$
u(c)=\frac{c^{1-\gamma}}{1-\gamma}
$$

where $\gamma$ is the coefficient of relative risk aversion. The mathematical properties of this utility function are such that higher values of $\gamma$ equate to higher levels of risk aversion.

In bidding in an auction, a farmer's actual earnings are uncertain though farmers can use the information at their disposal to estimate the probability of different possible earnings outcomes. Accordingly, we assume farmers evaluate uncertain outcomes by calculating expected utility;

$$
E[u(c)]=\sum_{a \in A} \operatorname{Pr}(a) u\left(c_{a}\right)=\sum_{a \in A} \operatorname{Pr}(a) \cdot \frac{c_{a}^{1}-\gamma}{1-\gamma}
$$

where $A$, is the set of possible earnings outcomes, $\operatorname{Pr}(a)$ is the probability of earnings outcome $a$ occurring and $c a$ is income in state $a$.

In an auction a farmer's key decision relates to the payment they request in the event that they are successful. We shall label that bid amount, $b$. Of course, farmers want to earn as much as possible which encourages them to enter a high $b$. At the same time, the probability of winning falls the higher the level of $b$, since asking for a higher payment makes a bid less attractive relative to other farmers' bids. In formulating a bid a farmer must weigh up these counter-acting factors. More formally, we can therefore write the farmer's bidding problem as;

$$
\operatorname{Max}_{b}: \operatorname{Pr}(\operatorname{win} \mid b) \cdot\left(\frac{b^{1-\gamma}}{1-\gamma}\right)+(1-\operatorname{Pr}(\operatorname{win} \mid b)) \cdot\left(\frac{c^{1-\gamma}}{1-\gamma}\right)
$$

A final complicating factor comes in the form of transaction costs. In our analyses we assume that bidding in the auction is itself a costly undertaking. Indeed, the process of entering a bid imposes costs of $t c$ on a farmer, costs that they can avoid if they decide not to participate in the auction. If a farmer believes they have little chance of winning, then it 
could well be a good strategy to avoid incurring the transaction costs by not entering a bid. Accordingly, in our simulator the decision problem faced by each farmer amounts to solving the following problem:

$$
\operatorname{Max}_{b, \theta}: \theta\left[\operatorname{Pr}(\operatorname{win} \mid b) \cdot\left(\frac{(b-t c)^{1-\gamma}}{1-\gamma}\right)+\left(1-\operatorname{Pr}(\operatorname{win} \mid b) \cdot\left(\frac{(c-t c)^{1-\gamma}}{1-\gamma}\right)\right]+(1-\theta)\left[\frac{c^{1-\gamma}}{1-\gamma}\right]\right.
$$

where $\theta$ is a binary decision variable taking the value 1 if the farmer decides to bid and 0 otherwise. Notice that the introduction of transaction costs has two main effects on the decision problem. First it means that the minimum payment required by a farmer to make it worthwhile bidding in the auction must at least cover their foregone income and the transaction cost; $b>c+t c$. Second, it may lead to some farmers deciding not to participate in the auction.

Landholders' bidding behaviour is not only shaped by their own information but also by the prior information they hold on the costs and qualities of other farms. We assume that each landholder has imperfect knowledge of those details. If a landholder's prior information is based on an exact representative sample of all landholders then it will provide them with an unbiased assessment of the cost and quality distribution. In our simulation we assume that each farm has a biased sample that we suspect will be made up of other farms that have costs and qualities relatively more like their own. Allowing for such bias reflects our expectation that landholders will know relatively more about the costs and qualities of farms in their local region which are likely to be more like their own.

In addition to the information farmers have, their bidding behaviour is also shaped by their strategic bidding logic. We borrow the intuition behind the level-k literature (also known as cognitive hierarchy theory) (Nagel 1995; Stahl and Wilson 1995; Camerer et al. 2004; Crawford and Iriberri 2007) and assume that bidders have varying levels of sophistication in their logic when determining their auction bidding behaviour.

Landholders with level-0 sophistication only consider their own circumstances. They decide upon a level of bid-shading that they feel is suitable for joining the PES scheme. That level of bid shading is from a random draw from a uniform distribution on the range 5-25\%. Landholders with level-1 sophistication consider how their chances of winning might be affected by other landholders' bids. The level-1 landholders assume other buyers are only using level-0 sophistication. Of course, a landholder might go one step further and employ another level of bidding sophistication-level-2 sophistication. Landholders with level-2 sophistication would assume that each other landholder decided on a bid using level-1 bidding sophistication. This process recurs through increasing rounds of sophistication. In the auction simulator, we randomly assign each landholder to a particular sophistication level such that roughly $15 \%$ use level- $0,50 \%$ use level-1 or level-2 sophistication and $35 \%$ use level-3 or more bidding sophistication.

\section{References}

Armsworth PR, Acs S, Dallimer M, Gaston KJ, Hanley N, Wilson P (2012) The cost of policy simplification in conservation incentive programs. Ecol Lett 15(5):406-414. https://doi.org/10.111 1/j.1461-0248.2012.01747.x

Asquith NM, Vargas MT, Wunder S (2008) Selling two environmental services: in-kind payments for bird habitat and watershed protection in Los Negros, Bolivia. Ecol Econ 65(4):675-684. https://doi. org/10.1016/j.ecolecon.2007.12.014 
Banerjee S, de Vries FP, Hanley N, van Soest DP (2014) The impact of information provision on agglomeration bonus performance: an experimental study on local networks. Am J Agric Econ 96(4):1009_ 1029. https://doi.org/10.1093/ajae/aau048

Bode M, Probert W, Turner WR, Wilson KA, Venter O (2011) Conservation planning with multiple organizations and objectives. Conserv Biol 25(2):295-304. https://doi.org/10.1111/j.1523-1739.2010.01610.x

Camerer CF, Ho TH, Chong JK (2004) A cognitive hierarchy model of games. Q J Econ 119(3):861-898. https://doi.org/10.1162/0033553041502225

Chan KMA, Shaw MR, Cameron DR, Underwood EC, Daily GC (2006) Conservation planning for ecosystem services. PLoS Biol 4(11):2138-2152. https://doi.org/10.1371/journal.pbio.0040379

Crawford VP, Iriberri N (2007) Level-k auctions: can a nonequilibrium model of strategic thinking explain the winner's curse and overbidding in private-value auctions? Econometrica 75(6):1721-1770. https:// doi.org/10.1111/j.1468-0262.2007.00810.x

Day B, Couldrick L (2013) Payment for ecosystem services pilot project: the Fowey river improvement auction. Defra, London

Deal RL, Cochran B, LaRocco G (2012) Bundling of ecosystem services to increase forestland value and enhance sustainable forest management. For Policy Econ 17:69-76. https://doi.org/10.1016/j.forpo 1.2011.12.007

Defra (2013) Developing the potential for payments for ecosystem services: an action plan. Department for Environment, Food and Rural Affairs, London

Elliott J, Day B, Jones G, Binner A, Smith G, Skirvin D, Boatman ND, Tweedie F (2015) Scoping the strengths and weaknesses of different auction and PES mechanisms for Countryside Stewardship, Defra, London. Reference No: LM0105

Engel S, Pagiola S, Wunder S (2008) Designing payments for environmental services in theory and practice: an overview of the issues. Ecol Econ 65(4):663-674

FAO (2007) The state of food and agriculture 2007, paying farmers for environmental services. FAO agriculture series no. 38, Rome. ISSN 0081-4539

Fauzi A, Anna Z (2013) The complexity of the institution of payment for environmental services: a case study of two Indonesian PES schemes. Ecosyst Serv 6:54-63. https://doi.org/10.1016/j.ecose r.2013.07.003

Goldman RL, Thompson BH, Daily GC (2007) Institutional incentives for managing the landscape: inducing cooperation for the production of ecosystem services. Ecol Econ 64(2):333-343. https://doi. org/10.1016/j.ecolecon.2007.01.012

Kemkes RJ, Farley J, Koliba CJ (2010) Determining when payments are an effective policy approach to ecosystem service provision. Ecol Econ 69(11):2069-2074

Kirkpatrick JB (1983) An iterative method for establishing priorities for the selection of nature reserves: an example from Tasmania. Biol Conserv 25(2):127-134. https://doi.org/10.1016/0006-3207(83)90056-3

Kline JD, Mazzotta MJ (2012) Evaluating tradeoffs among ecosystem services in the management of public lands. United States Department of Agriculture, Forest Service, Pacific Northwest Research Station, General Technical Report PNW-GTR-865

LaRocco G, Deal RL (2011) Giving credit where credit is due: increasing landowner compensation for ecosystem services. General technical reports PNW-GTR-842. Department of Agriculture, Forest Service, Pacific Northwest Research Station, Portland, OR

Laurance WF, Delamonica P, Laurance SG, Vasconcelos HL, Lovejoy TE (2000) Conservation: rainforest fragmentation kills big trees. Nature 404(6780):836. https://doi.org/10.1038/35009032

Laurance WF, Lovejoy TE, Vasconcelos HL, Bruna EM, Didham RK, Stouffer PC, Gascon C, Bierregaard RO, Laurance SG, Sampaio E (2002) Ecosystem decay of amazonian forest fragments: a 22-year investigation. Conserv Biol 16(3):605-618. https://doi.org/10.1046/j.1523-1739.2002.01025.x

Lawton JH, Brotherton PNM, Brown VK, Elphick C, Fitter AH, Forshaw J, Haddow RW, Hilborne S, Leafe RN, Mace GM, Southgate MP, Sutherland WJ, Tew TE, Varley J, Wynne GR (2010) Making space for nature: a review of England's wildlife sites and ecological network. Report to Defra

Lewis DJ, Plantinga AJ, Nelson E, Polasky S (2011) The efficiency of voluntary incentive policies for preventing biodiversity loss. Resour Energy Econ 33(1):192-211. https://doi.org/10.1016/j.resen eeco.2010.04.012

Maes J, Paracchini ML, Zulian G, Dunbar MB, Alkemade R (2012) Synergies and trade-offs between ecosystem service supply, biodiversity, and habitat conservation status in Europe. Biol Conserv 155:1-12. https://doi.org/10.1016/j.biocon.2012.06.016

Mettepenningen E, Verspecht A, Van Huylenbroeck G (2009) Measuring private transaction costs of European agri-environmental schemes. J Environ Plan Manag 52(5):649-667. https://doi. org/10.1080/09640560902958206 
Millennium Ecosystem Assessment (2005) Ecosystems and human well-being: synthesis. Island Press, Washington, DC

Mitchell MGE, Bennett EM, Gonzalez A (2013) Linking landscape connectivity and ecosystem service provision: current knowledge and research gaps. Ecosystems 16(5):894-908. https://doi.org/10.1007/ s10021-013-9647-2

Mitchell MGE, Suarez-Castro AF, Martinez-Harms M, Maron M, McAlpine C, Gaston KJ, Johansen K, Rhodes JR (2015) Reframing landscape fragmentation's effects on ecosystem services. Trends Ecol Evol 30(4):190-198. https://doi.org/10.1016/j.tree.2015.01.011

Nagel R (1995) Unraveling in guessing games: an experimental study. Am Econ Rev 85(5):1313-1326

Nalle DJ, Arthur JL, Montgomery C, Sessions J (2002) Economic and spatial impacts of an existing reserve network on future augmentation. Environ Model Assess 7(2):99-105. https://doi.org/10.1023/A:10156 97632040

Nalle DJ, Montgomery C, Arthur JL, Polasky S, Schumaker NH (2004) Modeling joint production of wildlife and timber. J Environ Econ Manag 48(3):997-1017

Natural Capital Committee (2015) The state of natural capital: protecting and improving natural capital for prosperity and wellbeing, Third report to the Economic Affairs Committee. Defra, London

Nelson E, Polasky S, Lewis DJ, Plantinga AJ, Lonsdorf E, White D, Bael D, Lawler JJ (2008) Efficiency of incentives to jointly increase carbon sequestration and species conservation on a landscape. Proc Natl Acad Sci USA 105(28):9471-9476. https://doi.org/10.1073/pnas.0706178105

Onal H, Briers RA (2002) Incorporating spatial criteria in optimum reserve network selection. Proc R Soc B Biol Sci 269(1508):2437-2441. https://doi.org/10.1098/rspb.2002.2183

Önal H, Briers RA (2005) Designing a conservation reserve network with minimal fragmentation: a linear integer programming approach. Environ Model Assess 10(3):193-202. https://doi.org/10.1007/s1066 6-005-9009-3

Parkhurst GM, Shogren JF (2007) Spatial incentives to coordinate contiguous habitat. Ecol Econ 64(2):344-355

Parkhurst GM, Shogren JF, Bastian C, Kivi P, Donner J, Smith RBW (2002) Agglomeration bonus: an incentive mechanism to reunite fragmented habitat for biodiversity conservation. Ecol Econ 41(2):305-328

Perrot-Maître D (2006) The Vittel payments for ecosystem services: a "perfect" PES case?. International Institute for Environment and Development, London

Polasky S, Nelson E, Lonsdorf E, Fackler P, Starfield A (2005) Conserving species in a working landscape: land use with biological and economic objectives. Ecol Appl 15(4):1387-1401. https://doi. org/10.1890/03-5423

Polasky S, Nelson E, Camm JD, Csuti B, Fackler P, Lonsdorf E, Montgomery C, White D, Arthur J, GarberYonts B, Haight R, Kagan J, Starfield A, Tobalske C (2008) Where to put things? Spatial land management to sustain biodiversity and economic returns. Biol Conserv 141(6):1505-1524. https://doi. org/10.1016/j.biocon.2008.03.022

Polasky S, Lewis DJ, Plantinga AJ, Nelson E (2014) Implementing the optimal provision of ecosystem services. Proc Natl Acad Sci USA 111(17):6248-6253. https://doi.org/10.1073/pnas.1404484111

Pressey RL, Possingham HP, Day JR (1997) Effectiveness of alternative heuristic algorithms for identifying indicative minimum requirements for conservation reserves. Biol Conserv 80(2):207-219. https://doi. org/10.1016/S0006-3207(96)00045-6

Rubinstein A (1982) Perfect equilibrium in a bargaining model. Econometrica 50(1):97-109. https://doi. org/10.2307/1912531

Salzman J (2009) A policy maker's guide to designing payments for ecosystem services. Duke Law Faculty Scholarship, Paper 2081

Salzman J (2010) Designing payments for ecosystem services. In: PERC policy series no. 48

Sánchez-Azofeifa GA, Pfaff A, Robalino J, Boomhower JP (2007) Costa Rica's payment for environmental services program: intention, implementation, and impact. Conserv Biol 21(5):1165-1173. https://doi. org/10.1111/j.1523-1739.2007.00751.x

Schilizzi S, Latacz-Lohmann U (2012) Evaluating conservation auctions with unknown bidder costs: the Scottish fishing vessel decommissioning program. Land Econ 88(4):658-673

Schomers S, Matzdorf B (2013) Payments for ecosystem services: a review and comparison of developing and industrialized countries. Ecosyst Serv 6:16-30. https://doi.org/10.1016/j.ecoser.2013.01.002

Sen A, Harwood AR, Bateman IJ, Munday P, Crowe A, Brander L, Raychaudhuri J, Lovett AA, Foden J, Provins A (2014) Economic assessment of the recreational value of ecosystems: methodological development and national and local application. Environ Resour Econ 57(2):233-249. https://doi. org/10.1007/s10640-013-9666-7 
Smith G, Day B (2018) Addressing the collective action problem in multiple-purchaser PES: an experimental investigation of negotiated payment contributions. Ecol Econ 144:36-58. https://doi.org/10.1016/j. ecolecon.2017.07.020

Stahl DO, Wilson PW (1995) On players models of other players-theory and experimental-evidence. Games Econ Behav 10(1):218-254. https://doi.org/10.1006/game.1995.1031

Steinman AD, Denning R (2005) The role of spatial heterogeneity in the management of freshwater resources. In: Lovett GM, Turner MG, Jones CG, Weathers KC (eds) Ecosystem function in heterogeneous landscapes. Springer, New York, pp 367-387

Stoneham G, Chaudhri V, Ha A, Strappazzon L (2003) Auctions for conservation contracts: an empirical examination of Victoria's BushTender trial. Aust J Agric Resour Econ 47(4):477-500

Tóth SF, McDill ME (2008) Promoting large, compact mature forest patches in harvest scheduling models. Environ Model Assess 13(1):1-15. https://doi.org/10.1007/s10666-006-9080-4

UK National Ecosystem Assessment (2011) The UK national ecosystem assessment: synthesis of the key findings. UNEP-WCMC, Cambridge

Venter O, Laurance WF, Iwamura T, Wilson KA, Fuller RA, Possingham HP (2009) Harnessing carbon payments to protect biodiversity. Science 326(5958):1368. https://doi.org/10.1126/science.1180289

Wätzold F, Drechsler M (2014) Agglomeration payment, agglomeration bonus or homogeneous payment? Resour Energy Econ 37:85-101. https://doi.org/10.1016/j.reseneeco.2013.11.011

Williams JC, Snyder SA (2005) Restoring habitat corridors in fragmented landscapes using optimization and percolation models. Environ Model Assess 10(3):239-250. https://doi.org/10.1007/s1066 6-005-9003-9

Williams JC, ReVelle CS, Levin SA (2005) Spatial attributes and reserve design models: a review. Environ Model Assess 10(3):163-181. https://doi.org/10.1007/s10666-005-9007-5

Woodward RT (2011) Double-dipping in environmental markets. J Environ Econ Manag 61(2):153-169

Publisher's Note Springer Nature remains neutral with regard to jurisdictional claims in published maps and institutional affiliations. 